\title{
The sociopolitical history and physiological underpinnings of skull deformation
}

\author{
*Amit Ayer, B.S., ${ }^{1}$ Alexander Campbell, M.Phil., ${ }^{2}$ Geoffrey Appelboom, M.D., ${ }^{1}$ \\ Brian Y. Hwang, B.A., ${ }^{1}$ Michael McDowell, B.S., ${ }^{1}$ Matthew Piazza, B.A., 1 \\ Neil A. Feldstein, M.D., ${ }^{1}$ And Richard C. E. Anderson, M.D. ${ }^{1}$ \\ ${ }^{1}$ Department of Neurological Surgery, Columbia University College of Physicians \& Surgeons, New York, \\ New York; and ${ }^{2}$ Department of History, Trinity Hall, Cambridge, United Kingdom
}

\begin{abstract}
In this report, the evidence, mechanisms, and rationale for the practice of artificial cranial deformation (ACD) in ancient Peru and during Akhenaten's reign in the 18th dynasty in Egypt (1375-1358 BCE) are reviewed. The authors argue that insufficient attention has been given to the sociopolitical implications of the practice in both regions. While evidence from ancient Peru is widespread and complex, there are comparatively fewer examples of deformed crania from the period of Akhenaten's rule. Nevertheless, Akhenaten's own deformity, the skull of the so-called "Younger Lady" mummy, and Tutankhamen's skull all evince some degree of plagiocephaly, suggesting the need for further research using evidence from depictions of the royal family in reliefs and busts. Following the anthropological review, a neurosurgical focus is directed to instances of plagiocephaly in modern medicine, with special attention to the conditions' etiology, consequences, and treatment. Novel clinical studies on varying modes of treatment will also be studied, together forming a comprehensive review of ACD, both in the past and present.
\end{abstract} (DOI: $10.3171 / 2010.9$.FOCUS10202)

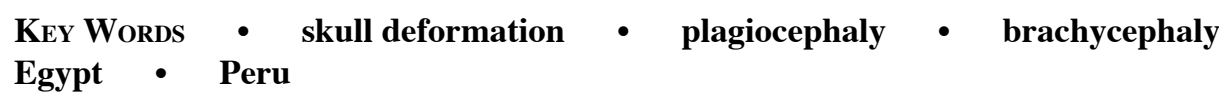

$\mathrm{N}$ ICHTER and colleagues ${ }^{21}$ suggested that the idiom "heads of state" might have derived from the practice of the political elite's molding the heads of their offspring to differentiate themselves from the rest of a populace. Studies of human remains from ancient Peru and Egypt have not drawn attention to the political implications of artificial skull deformation, whether artistic or real. These perceptual or structural cranial characteristics can be derived from a variety of factors that will be elaborated upon throughout the course of this paper. First, physical evidence from ancient Peru and Egypt is reviewed. Second, the discussion draws attention to ways in which the politics of a society might help to explain the rationale behind ACD. Ancient Peruvian and Egyptian evidence suggests that physical or artistic manipulation of skulls was undertaken not just to reinforce social distinctions, but also to entrench political power. It is argued that approaching perceptions and portrayals of skulls could also complement discussions of artificially deformed crania. The techniques used in ACD will then be elaborated upon, with a discussion of the physiological basis, consequences, and treatments of plagiocephaly.

Abbreviation used in this paper: $\mathrm{ACD}=$ artificial cranial deformation.

* Mr. Ayer and Mr. Campbell contributed equally to this work.

\section{Artificial Cranial Deformation by Region}

The earliest evidence of the practice of ACD comes from remains of the Mousterian people from Shanidar in Iraq and dates from the Middle Paleolithic period (approximately $300,000-30,000$ years ago)..$^{30}$ The practice in ancient Peru and Egypt shall be addressed here, because evidence from the latter society greatly differs from that of the former in terms of frequency. Anthropologists studying the 2 societies, nonetheless, have accounted for the practice in similar ways.

\section{Ancient Peru}

The first evidence of an artificially deformed skull in Peru was found near Uricocha, dated to the period between 6000 and $7000 \mathrm{BCE}$, suggesting that the ancient Peruvians introduced the practice on the continent. ${ }^{7,26} \mathrm{~A}$ collection of 500 Peruvian skulls in Paris only contains 60 free of deformation (Figs. 1 and 2). ${ }^{5}$ In some cases, dig sites yielded human remains with $90 \%$ of the skulls deformed. ${ }^{3,5,26}$ Head shape appears to have demarcated membership within a group in a large, complex society, whereas in smaller societies, head shape demarcated social group differences. There is a "complex" archaeological record in the region according to Dingwall, ${ }^{5}$ which Imbelloni ${ }^{13}$ divided into 7 distinct regions according to, among other things, the method used. Intentional defor- 


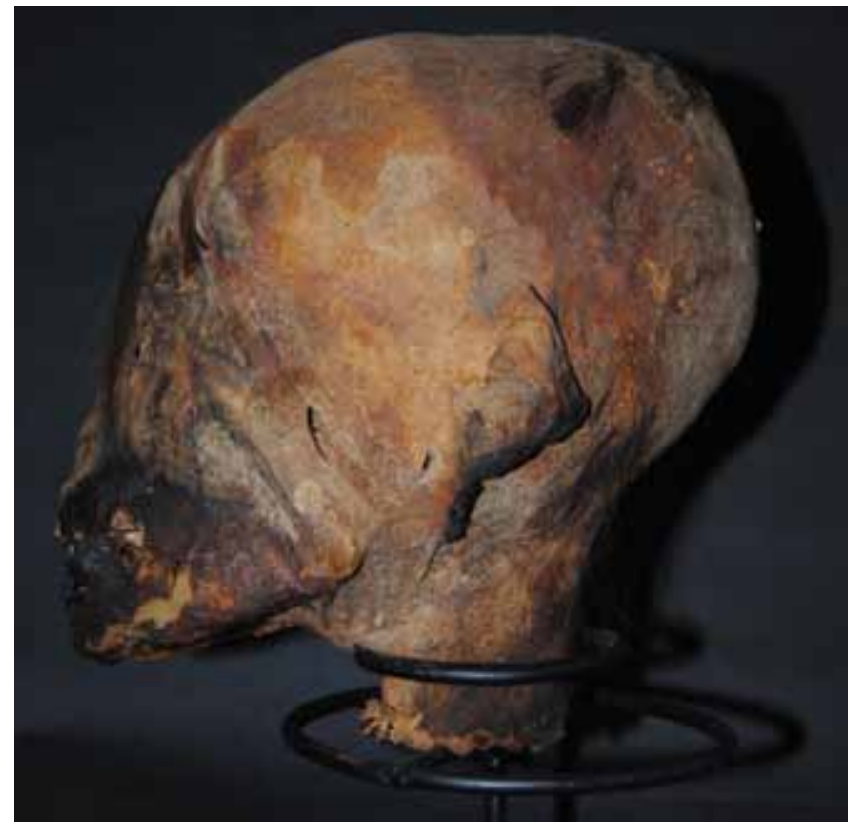

Fıg. 1. Lateral view of ancient Peruvian skull. Courtesy of the Université Libre de Bruxelles (Bruxelles, Belgium).

mation was accomplished either by compression of the front and back of the head with boards and pads, tightly bandaging the head and progressively adjusting the bandages, or by restraining the child against a cradleboard. ${ }^{26}$

Anthropologists have explained ACD as a method of defining membership of social or ethnic groups. Tommaseo and Drusini ${ }^{29}$ argued that the practice could enforce a hierarchy or signify membership in a warrior class. Social distinctions, however, could also give the individual political power. In ancient Peru it has been suggested that as the ruling class became comfortable in power, they permitted some noble families to shape the skulls of their children, imitating the distinct features of the ruler's skull. ${ }^{5,8,26}$ While this may have entrenched the ruler's power, permitting an individual to show such allegiance would require the individual to take on a political role. Conversely, this privilege could have resulted in a proliferation of claims to rule the society. With more nobles eliciting the cranial characteristics of the ruler, the populace would no longer be able to differentiate between ruler and noble based upon that criterion.

\section{Ancient Egypt}

Although there is little archaeological evidence of ACD in Egypt before $600 \mathrm{CE}$, notable exceptions exist from the reign of Akhenaten (1375-1358 BCE) in the 18th dynasty. Studies of the morphology of Akhenaten's skull suggest that an acromegalic or macrocephalic disease may have deformed it. ${ }^{3,5}$ Akhenaten's queen, Nefertiti, is notably portrayed in busts and reliefs with apparent anterior plagiocephaly, although her mummy has not been discovered to verify this trait. The mummy of another of Akhenaten's consorts and the mother of Tutankhamen, the so-called "Younger Lady" mummy, also possesses a cranial deformity. ${ }^{11}$ Finally, the mummy of Tutankhamen, Akhenaten's apparent successor, was discovered at the

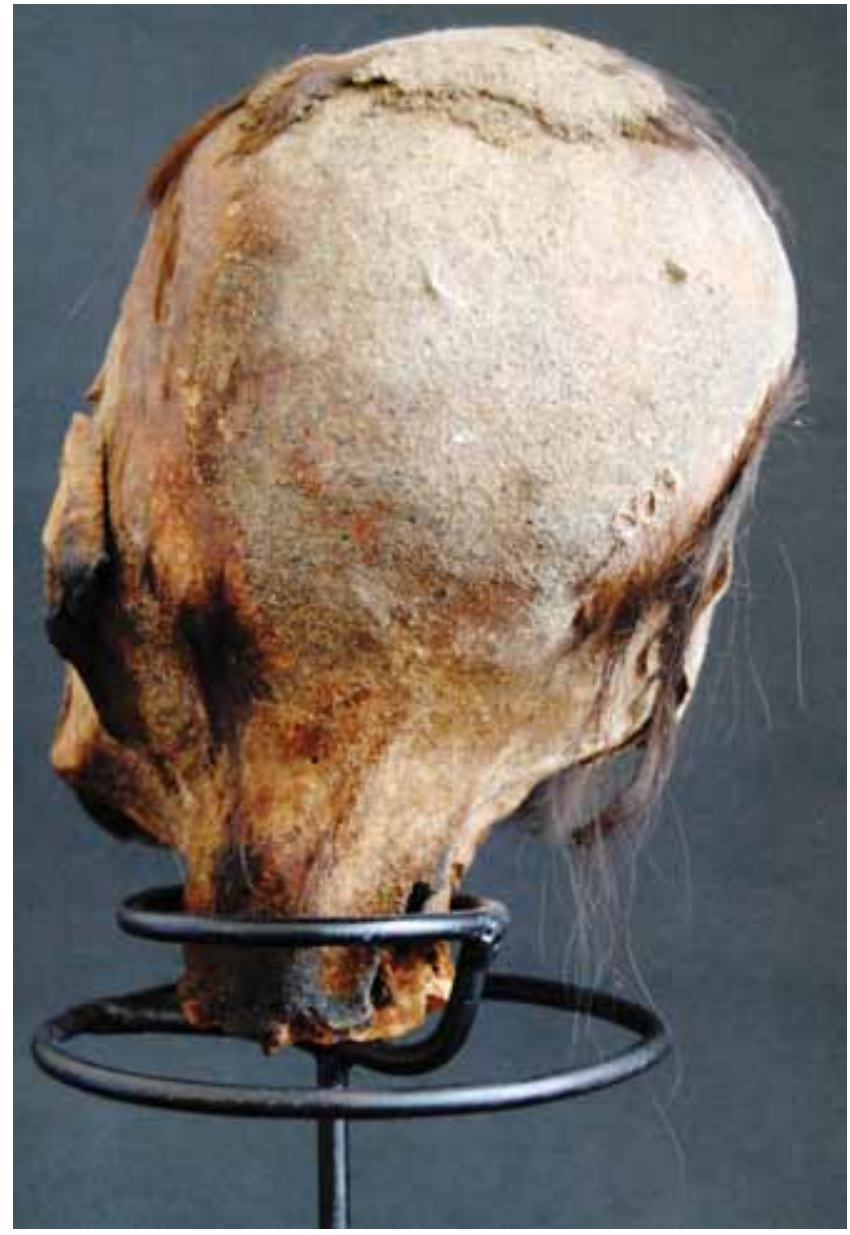

Fıg. 2. Posterior view of ancient Peruvian skull. Courtesy of the Université Libre de Bruxelles.

start of the 20th century with a deformed cranium (Fig. 3). ${ }^{5}$ Although no current study addresses the methods that might have been used, the skulls elicit deformations characteristic of frontooccipital deformation.

Akhenaten ushered in a great religious, political, and artistic upheaval: the Amarna revolution. Government was centralized as the pharaoh dissolved local cults and turned Egypt into a monotheism worshipping Aten. Stylistic changes in depictions of the royal family were so drastic that it is believed they could only have occurred at the suggestion of the pharaoh. ${ }^{1}$ In particular, the cranial shape of the royal family and officials was distorted. ${ }^{3,5}$

Dingwall's ${ }^{5}$ claim that no physical evidence exists from the period surrounding Akhenaten's reign appears to be disproven by the skulls of the "Younger Lady" and Tutankhamen. Yet the artistic evidence should not be discredited. Depictions of members of the royal family, such as Nefertiti, may have deliberately been distorted so that they became linked to Akhenaten's growing power. Further research into the causes of Tutankhamen's deformed cranium may reveal that Akhenaten decided to physically deform his heir's head to legitimize his claim to the throne. The importance of distorting head shape, artistically or physically, may have been politically significant for Akhenaten. 


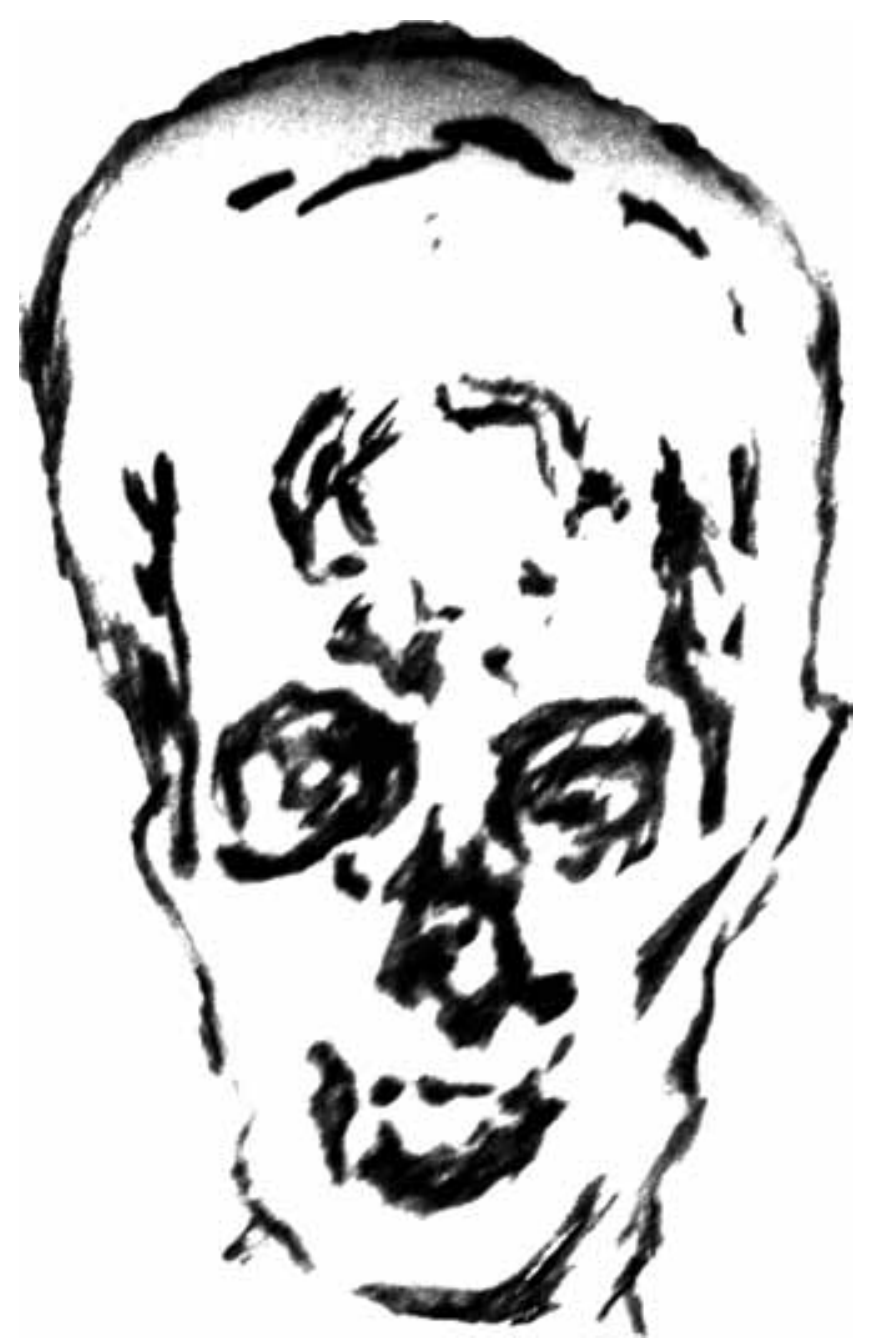

Fig. 3. Artistic reproduction of Tutankhamen's head shape based on a CT of his skull.

\section{Plagiocephaly in Modern Medicine}

Though societies may no longer manipulate the heads of their offspring to augment their political power, plagiocephaly continues to be a problem in developing children. Plagiocephaly refers to an asymmetrical head, wherein part of the head is flattened and part is round (Figs. 4, 5, and 6). In this section, we will review the mechanisms, intentional or unintentional, of skull deformation, physiological consequences, and treatment options.

\section{Mechanisms}

Deformation occurs by an alteration of the direction of intrinsic growth of the human head. Physiologically, as the brain grows, the developing bones are pushed outward by its expansion, while osteogenic membranes at the sutures produce bone equal to this displacement. This functions to increase bone size but maintain surrounding articulations. ${ }^{8}$ Occasionally helping to fill the space are intercalary, "wormian" bones, compensating for the increased surface area. ${ }^{6,23}$ Once fused, the sutures remain in their position.

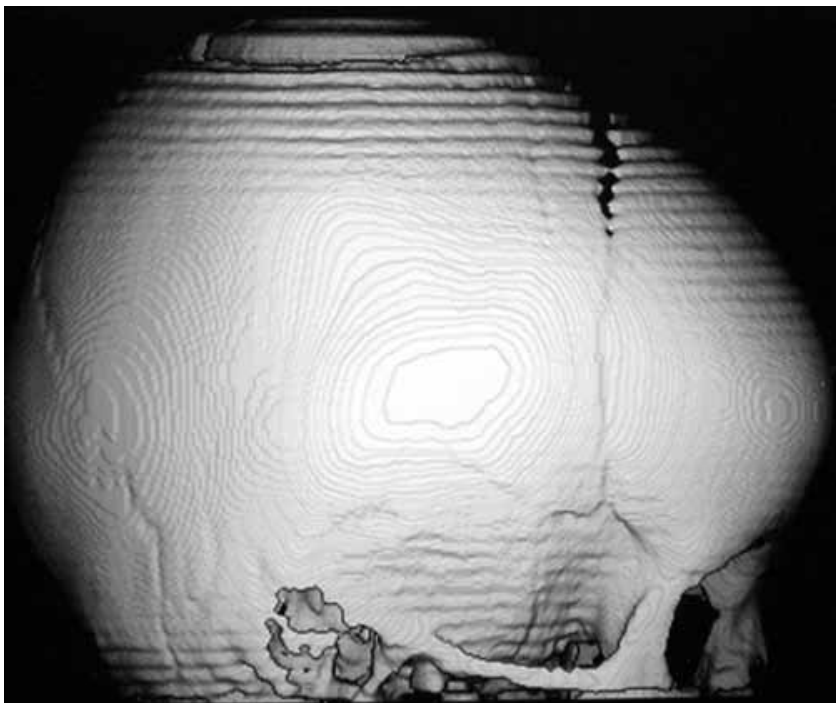

FIG. 4. Lateral view of 3D CT reconstruction of plagiocephalic skull.

\section{Artificial Deformation}

According to Imbelloni, ${ }^{13}$ the skull may be artificially shaped through either tabular or anular deformation. Tabular, or "flat-head" deformation involves skull manipulation by compressing the frontal and occipital parts of the head with oblique or erect fixed boards and pads. This produces frontooccipital flattening and lateral bulging of the head. Oblique deformation occurs when oblique boards compress the skull at the inion, whereas erect deformation is accomplished with vertical boards centered on the lambdoid suture. ${ }^{26}$ The deforming apparatus can prevent blood flow to the developing areas and cause necrosis of the occipital bone..$^{9}$ Anular deformation

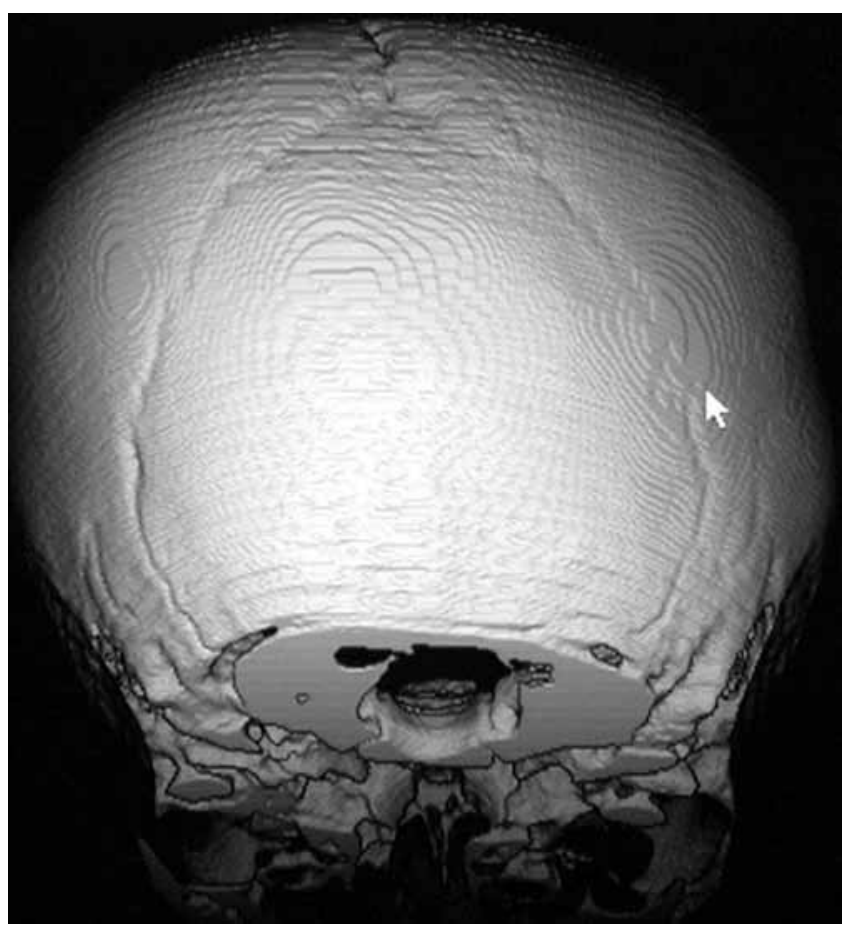

FIG. 5. Posterior view of 3D CT of plagiocephalic skull. 


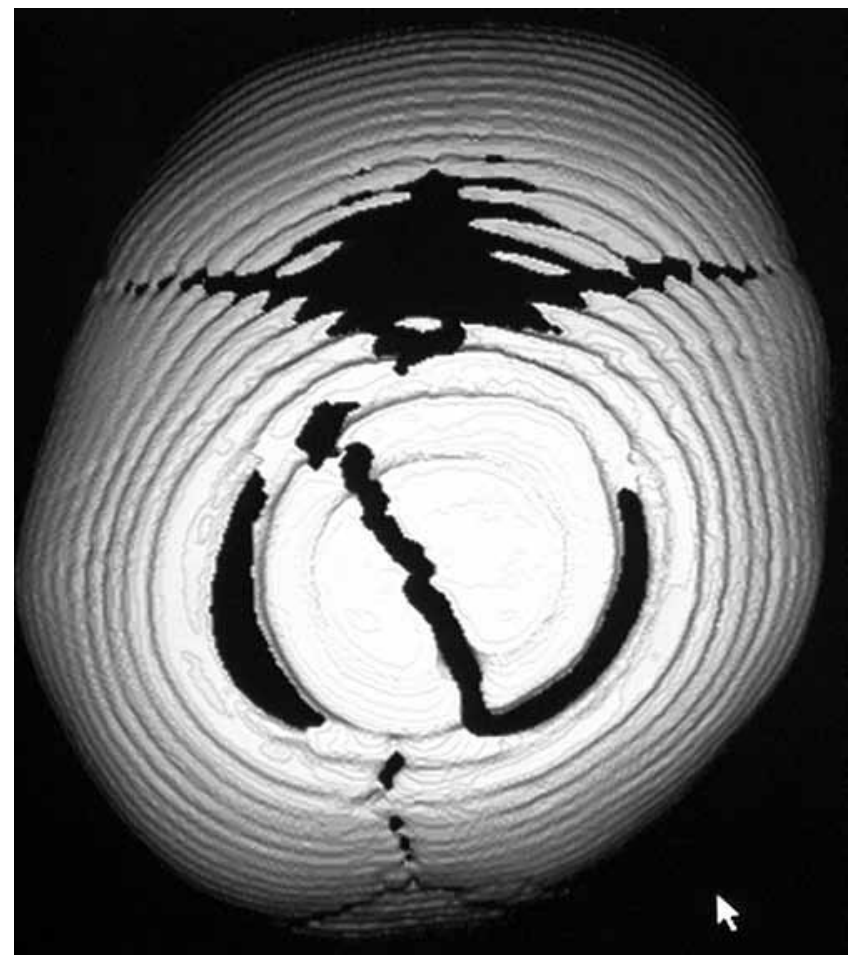

Fıg. 6. Inferior view of 3D CT of plagiocephalic skull.

is the consequence of wrapping a compressive bandage around the skull, leading to a conical cranium.

\section{Pathological Deformation}

Plagiocephaly continues to affect nearly $10 \%$ of all children, with a large rise in incidence beginning in 1992 corresponding with the initiation of the "Back to Sleep" campaign by the American Academy of Pediatrics. This campaign urged parents to position their children supine during sleep to decrease the incidence of sudden infant death syndrome..$^{2,15,18}$ The impact of this initiative can be seen in the near elimination of frontal plagiocephaly (attributed to prone sleeping) and a concomitant rise in the incidence of posterior plagiocephaly. In addition to a supine sleep position, the uterine environment has been implicated in the development of plagiocephaly. ${ }^{19}$ Intrauterine factors may compromise neck musculature or be the primary cause of skull malformation, leading to a positional sleep preference that may exacerbate plagiocephaly. Maternal primiparity, multiple births, and congenital torticollis are all associated with the development of plagiocephaly due to constraints of the maturing fetus. ${ }^{14}$ Factors compromising fetal movement may lead to pressure on a specific cranial area, thereby conferring plagiocephaly on the newborn. In addition, many infants suffering from neurological impairment, oligohydramnios, or undergoing forceps- or vacuum-assisted delivery may also have plagiocephaly. ${ }^{10,22}$ Interestingly, posterior deformational plagiocephaly has a right-sided prevalence, perhaps due to the fetus's descent into the pelvis, which may limit growth of the right occiput and left frontal areas. In addition, males have a higher risk of developing plagiocephaly, which is suggested to be due to the larger cranial size and comparative inflexibility of the male fetus..$^{22}$

\section{Sequelae}

The consequences of cranial deformation are generally resolved if the infant is positioned so that he or she is lying on the side opposite to the plagiocephalic side. However, without positional maneuvering off the flattened area, the problem may perpetuate or worsen. Deformities may persist into adolescence, but such occurrences are rare, with few current cases acknowledged by patients. ${ }^{4}$ One frequent comorbidity is torticollis, or "wryneck," which is most commonly due to an imbalanced tightness of the sternocleidomastoid muscle. A 371-patient prospective case series correlated congenital muscular torticollis with deformational plagiocephaly $(\mathrm{p}=0.043)$, and suggested that the incidence of "torticollis/sternocleidomastoid imbalance in deformational plagiocephaly" may be underreported. ${ }^{25}$ Fortunately, muscular torticollis can be successfully managed with physical therapy in nearly all cases. Several other conditions have been reported to be associated with plagiocephaly, but it is important to recognize that none have been demonstrated to have a causal relationship. For example, a recent small case-control study compared motor development in infants with and without positional plagiocephaly, and suggested a possible risk of motor delay in infants with this condition. ${ }^{17}$ In addition, a 470-patient case-control study assessed neurodevelopment in infants with and without plagiocephaly at 6 months of age. Deformational plagiocephaly was associated with a decrement in Bayley Scales of Infant Development scores $(\mathrm{p}<0.001)$, most significantly evident in motor functions. ${ }^{27}$ It is likely, however, that any difference in motor development between these 2 groups is simply due to spending less time in the prone position, and not due to the positional plagiocephaly. In addition to motor development, a 1259-patient retrospective study showed a trend correlating deformational plagiocephaly with otitis media, possibly because of plagiocephalic developmental alteration of the eustachian tube. ${ }^{24}$ Lastly, strabismus has been reported to be associated with frontal plagiocephaly, possibly due to traction on the ocular globe from underlying cranial malformations. ${ }^{4}$ Fortunately, deformational frontal plagiocephaly has been nearly completely eliminated since the initiation of the Back to Sleep program. Overall, despite several studies demonstrating associations between positional plagiocephaly and other conditions, no good-quality evidence supports the hypothesis that plagiocephaly is the cause.

\section{Treatment}

Due to parental concerns about appearance and the perceived comorbidities associated with plagiocephaly, treatment is often sought for these conditions. Suggested care for affected patients include reassurance, positioning, and, on occasion, external orthotic devices. ${ }^{4}$ Positioning refers to the facilitated placement of an infant's head on the nonflattened side when lying down; this fixation occurs with the use of wraps, foam wedges, or strategic positioning implemented by the caregiver. A recent randomized controlled trial used a Safe T Sleep device compared with positioning strategies, with no significant dif- 
ference found..$^{12}$ External orthotic devices, such as skull bands or helmets, use strategically placed pads to guide the intrinsic growth of the skull. These devices are worn for about 23 hours per day and are custom-fit to the child's head. ${ }^{4}$ Some studies have shown that these skull-molding helmets, which work in a fundamentally similar mechanism to the tabular artificial deformation method, may be more effective in the treatment of plagiocephaly than positioning methods, as measured by improvements in the cephalic index score. ${ }^{28}$ However, controversy surrounds these helmets because of their significant expense and the lack of controls and long-term follow-up in most studies. ${ }^{4}$ Helmets have been shown to be effective in short-term studies, with a 114-patient prospective study reporting a $17 \%$ correction of transcranial asymmetry $(\mathrm{p}<0.001) .{ }^{20}$ Another study recently compared parental opinion to the results of topographic laser head scans, assessing real versus perceived improvements with skull-molding therapy. Interestingly, parents reported more improvement posttherapy than was identified with topographical scanning, suggesting that parental bias plays a significant role in reported outcomes. ${ }^{16}$

\section{Conclusions}

From its origins in ancient Peru and ancient Egypt to the increasing prevalence in modern times, skull deformation continues to exhibit relevance in anthropological and medical contexts. Recent medical studies detailing consequences of skull deformation should inform future anthropological studies of ancient remains. A discussion of the rationale behind the practice in the light of political contexts might broaden our understanding of this worldwide practice of ACD, and could provide comfort for patients affected by skull deformation. Researchers should determine whether membership within a particular group, for example, also brought with it certain political responsibilities that may help to explain the rationale behind deforming the head of one's offspring. Further research may yield more fruitful results if, in investigating the political implications of head shape, researchers account for the wider cultural significance of head shapes and not merely those that have been intentionally deformed during infancy.

\section{Disclosure}

The authors report no conflict of interest concerning the materials or methods used in this study or the findings specified in this paper.

Author contributions to the study and manuscript preparation include the following. Conception and design: Appelboom, Ayer, Campbell. Acquisition of data: Ayer, Piazza. Analysis and interpretation of data: Ayer, Hwang, McDowell. Drafting the article: Ayer, Campbell, Anderson. Critically revising the article: Ayer, Campbell, Anderson. Reviewed final version of the manuscript and approved it for submission: Ayer, Campbell, Anderson. Administrative/techni$\mathrm{cal} / \mathrm{material}$ support: Ayer, Feldstein, Anderson. Study supervision: Appelboom, Ayer, Anderson.

\section{References}

1. Aldred C: Egypt: The Amarna Period and the End of the Eighteenth Dynasty. Cambridge: Cambridge University Press, 1971
2. American Academy of Pediatrics Task Force on Infant Positioning and SIDS: Positioning and sudden infant death syndrome (SIDS): update. Pediatrics 98:1216-1218, 1996

3. Arensburg B, Hershkovitz I: Cranial deformation and trephination in the middle east. Bull et Mem Soc Anthroplogie Paris 3:139-150, 1988

4. Bridges SJ, Chambers TL, Pople IK: Plagiocephaly and head binding. Arch Dis Child 86:144-145, 2002

5. Dingwall EJ: Artificial Cranial Deformation: A Contribution to the Study of Ethnic Mutilations. London: John Bale, Sons \& Danielsson Ltd, 1931

6. El-Najjar M, Dawson GL: The effect of artificial cranial deformation on the incidence of Wormian bones in the lambdoidal suture. Am J Phys Anthropol 46:155-160, 1977

7. Friede J: Descubrimiento Y Conquista del Nuevo Reino de Granada. Bogota: Ediciones Lerner, 1965, Vol 2

8. Gerszten PC, Gerszten E: Intentional cranial deformation: a disappearing form of self-mutilation. Neurosurgery 37:374 382,1995

9. Gottlieb K: Artificial cranial deformation and the increased complexity of the lambdoid suture. Am J Phys Anthropol 48: 213-214, 1978

10. Gracia A, Martínez-Lage JF, Arsuaga J-L, Martínez I, Lorenzo C, Pérez-Espejo M-Á: The earliest evidence of true lambdoid craniosynostosis: the case of "Benjamina", a Homo heidelbergensis child. Childs Nerv Syst 26:723-727, 2010

11. Hawass Z, Gad YZ, Ismail S, Khairat R, Fathalla D, Hasan N, et al: Ancestry and pathology in King Tutankhamun's family. JAMA 303:638-647, 2010

12. Hutchison BL, Stewart AW, de Chalain TB, Mitchell EA: A randomized controlled trial of positioning treatments in infants with positional head shape deformities. Acta Paediatr [epub ahead of print], 2010

13. Imbelloni J: Los pueblos deformadores de los andes. La deformacion intencional de la cabeza como arte y como elemento diagnostico de las culturas. Anales del Museo Argentino de Ciencias Naturales Bernandino Rivadavia 37:209-254, 1933

14. Joganic JL, Lynch JM, Littlefield TR, Verrelli BC: Risk factors associated with deformational plagiocephaly. Pediatrics 124:e1126-e1133, 2009

15. Kane AA, Mitchell LE, Craven KP, Marsh JL: Observations on a recent increase in plagiocephaly without synostosis. Pediatrics 97:877-885, 1996

16. Katzel EB, Koltz PF, Sbitany H, Emerson C, Girotto JA: Real versus perceived improvements of helmet molding therapy for the treatment of plagiocephaly. Plast Reconstr Surg 126: $19 \mathrm{e}-21 \mathrm{e}, 2010$

17. Kennedy E, Majnemer A, Farmer JP, Barr RG, Platt RW: Motor development of infants with positional plagiocephaly. Phys Occup Ther Pediatr 29:222-235, 2009

18. McKinney CM, Cunningham ML, Holt VL, Leroux B, Starr JR: A case-control study of infant, maternal and perinatal characteristics associated with deformational plagiocephaly. Paediatr Perinat Epidemiol 23:332-345, 2009

19. Moss SD: Nonsurgical, nonorthotic treatment of occipital plagiocephaly: what is the natural history of the misshapen neonatal head? J Neurosurg 87:667-670, 1997

20. Mulliken JB, Vander Woude DL, Hansen M, LaBrie RA, Scott RM: Analysis of posterior plagiocephaly: deformational versus synostotic. Plast Reconstr Surg 103:371-380, 1999

21. Nichter LSPJ, Persing JA, Horowitz JH, Morgan RF, Nichter MA, Edgerton MT: External cranioplasty: historical perspectives. Plast Reconstr Surg 77:325-332, 1986

22. Persing J, James H, Swanson J, Kattwinkel J, American Academy of Pediatrics Committee on Practice and Ambulatory Medicine, Section on Plastic Surgery and Section on Neurological Surgery: Prevention and management of positional skull deformities in infants. Pediatrics 112:199-202, 2003

23. Pucciarelli HM: Influence of experimental deformation on 
A. Ayer et al.

neurocranial wormian bones in rats. Am J Phys Anthropol 41:29-37, 1974

24. Purzycki A, Thompson E, Argenta L, David L: Incidence of otitis media in children with deformational plagiocephaly. $\mathbf{J}$ Craniofac Surg 20:1407-1411, 2009

25. Rogers GF, Oh AK, Mulliken JB: The role of congenital muscular torticollis in the development of deformational plagiocephaly. Plast Reconstr Surg 123:643-652, 2009

26. Schijman E: Artificial cranial deformation in newborns in the pre-Columbian Andes. Childs Nerv Syst 21:945-950, 2005

27. Speltz ML, Collett BR, Stott-Miller M, Starr JR, Heike C, Wolfram-Aduan AM, et al: Case-control study of neurodevelopment in deformational plagiocephaly. Pediatrics 125: e537-e 542, 2010

28. Teichgraeber JF, Seymour-Dempsey K, Baumgartner JE, Xia $\mathrm{JJ}$, Waller AL, Gateno J: Molding helmet therapy in the treat- ment of brachycephaly and plagiocephaly. J Craniofac Surg 15:118-123, 2004

29. Tommaseo M, Drusini A: Physical anthropology of two tribal groups of Amazonic Peru (with reference to artificial cranial deformation). Z Morphol Anthropol 74:315-333, 1984

30. Trinkaus E: Artificial cranial deformation in the Shanidar 1 and Shanidar 5 Neandertals. Curr Anthropol 23:198-199, 1982

Manuscript submitted August 15, 2010.

Accepted September 24, 2010.

Address correspondence to: Geoffrey Appelboom, M.D., Columbia University College of Physicians \& Surgeons, Neurological Institute of New York, 710 West 168th Street, Room 404, New York, New York 10032. email: ga2294@columbia.edu. 